\title{
Effect of kinematic and geometric parameters on the cut layer in a 5-axis machining of the sculptured surfaces
}

\author{
Wpływ parametrów kinematycznych i geometrycznych \\ na przekrój warstwy skrawanej \\ w pięcioosiowej obróbce powierzchni złożonych
}

\author{
MICHAK GDULA \\ JAN BUREK*
}

\begin{abstract}
Results of simulation studies made using the direct CAD method are presented. The significance of the influence of the toroidal cutter axis orientation parameters and curvature radius of the sculptured surface on the cut layer in a 5-axis milling of the convexconcave and concave-convex surfaces, was assessed.
\end{abstract}

KEYWORDS: 5-axis machining, toroidal cutter, cut layer, sculptured surfaces

The progress of the machine industry, and in particular aviation industry, is connected with development of modern construction materials and the production technology of geometrically complex parts [1, $2,5,8]$. Injection molds, dies, rotors or turbine blades are described by different types of surfaces, among which the most common are curvilinear surfaces, belonging to the group of so-called. sculptured surfaces $[5,8]$.

Sculptured surfaces have high demands on the accuracy of the shape and condition of the surface layer. The machining sometimes involves many complex operations, most often on CNC machines, in the simultaneous milling process, understood as simultaneous machining in five axes. Complex CAD systems and CAD/CAM systems are used for modeling sculptured surfaces and designing the process of their five-axis machining. These programs and expanded kinematically multi-axis machining centers enable machining of an object with any curvilinear contour [1, 2, 8].

The accuracy of shape and roughness of complex surfaces depend mainly on kinematic parameters (advance angle $\alpha$ and inclination angle $\beta$ ) of five-axis machining and geometric parameters of the surface to be machined (main curves considered in this work as radii $\rho_{1}$ and $\rho_{2}$ ), as illustrated in fig. 1 .

In addition, these parameters have a significant impact on the contact conditions in the contact zone of the toroidal cutter working surface and the machined surface, and thus on the course of five-axis milling $[3,4$, $6,7]$.

\footnotetext{
* Dr inż. Michał Gdula (gdulam@prz.edu.pl), dr hab. inż. Jan Burek prof. PRz (jburek@prz.edu.pl) - Politechnika Rzeszowska im. I. Łukasiewicza, Wydział Budowy Maszyn i Lotnictwa, Katedra Technik Wytwarzania i Automatyzacji
}

DOI: https://doi.org/10.17814/mechanik.2017.12.191

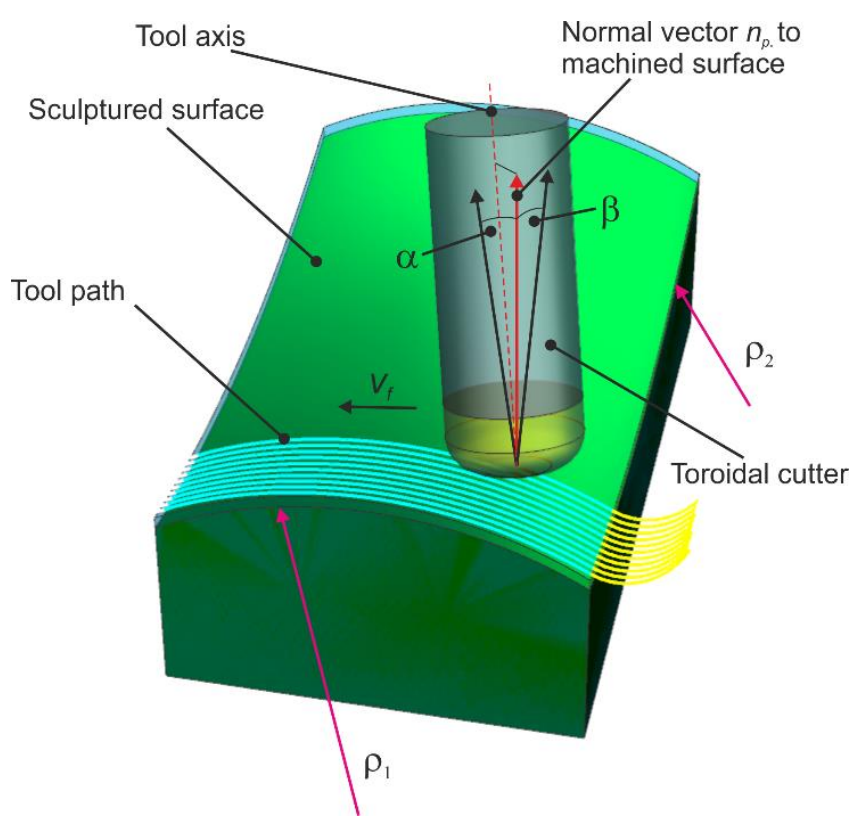

Fig. 1. Kinematic parameters of the five-axis milling process and geometrical parameters of the sculptured surface being machined

\section{Contact conditions of the toroidal cutter with the} machined surface

The contact conditions between the toroidal cutter and the surface to be machined result directly from the kinematics of the five-axis milling process. They are determined by:

- mutual position of the tool and the machined surface, implemented by kinematic angular parameters $\alpha$ and $\beta$ of the tool axis orientation with respect to the normal vector, e.g. to the machined surface (fig. 1),

- geometric parameters of the sculptured surface (radii of curvature $\rho_{1}$ and $\rho_{2}$ ),

- technological parameters of milling,

- shape and size of the cross-section of the cutting layer, which in turn determine the components of the cutting force acting on the tool and the workpiece, and thus affect the accuracy of the surface being machined.

In the five-axis milling process, the contact conditions of toroidal cutter working surface with the machined surface are constantly changing. This is mainly due to the geometrical relationship of the toroidal cutter, radius 
of curvature of currently machined surface profile as well as angular settings of the positioning parameters of the milling axis [2].

The paper [8] presents an analysis of the contact conditions of toroidal cutter with a machined surface - a projection of a contour of a toroidal cutter with machined surface in the direction of the feed onto $x z$ plane of the coordinate system (fig. 2).
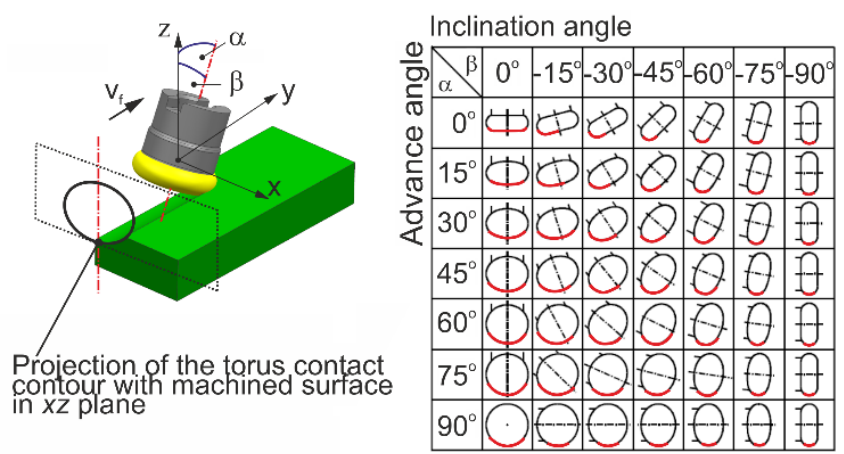

Fig. 2. Influence of angular parameters of the toroidal cutter axis orientation on the projection of the outline of the torus contact contour with the machined surface [5]

In the cases of the toroidal cutter axis orientation illustrated in fig. 2, the outline of the tool contact contour with the surface to be machined and the position of the contact point are variable, which in the case of machining the concave surfaces can cause the undercutting $[2,8]$.

Therefore, the works $[2,5,8]$ undertook an attempts to determine the minimum required angle of advance $\alpha_{\min }$ in machining of the concave sculptured surface to avoid undercutting (in machining of the convex surface, the undercutting does not occur). The authors of this papers approximate the scope of work of the toroidal cutter with the model of a spherical bowl, the radius of which is based on the projection of the outline contour of the cutter at the local point of contact between the tool and the machined surface (fig. 3).

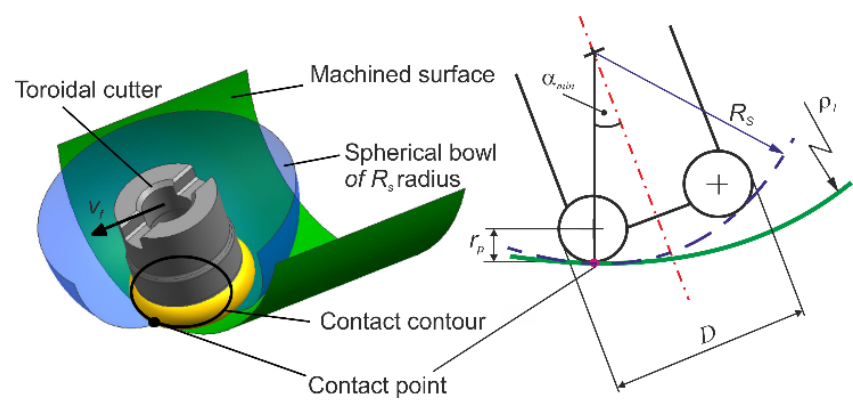

Fig. 3. Positioning of the cutter using a spherical bowl model [5]

Based on the diameter $D$ and the radius of the cutting insert $r_{p}$ of the toroidal cutter, as well as the radius of curvature $\rho_{1}$ of the machined surface profile in the feed direction, the value $\alpha_{\min }$ can be determined from the dependence:

$$
\alpha_{\min }=\arcsin \left(\frac{\frac{D}{2}-r_{p}}{\rho_{1}-r_{p}}\right)
$$

Therefore, for machining the sculptured surfaces with varying radii of curvature $\rho_{1}$ in the feed direction, the minimum required angle of advance $\alpha_{\min }$ should be continuously calculated.

Conditions affecting the contact zone between the toroidal cutter and the sculptured surface - i.e. orientation of the cutter axis and the curvature of surface significantly shape the cutting process. They determine the geometry of the cutting layer, and thus affect the components of the cutting forces that act on the tool and the workpiece. This has fundamental consequences for the accuracy of the shaped surface $[2,3,5]$.

So far, the significance of the influence of the advance angle $\alpha$, the inclination angle $\beta$ as well as the radii $\rho_{1}$ and $\rho_{2}$ of curvatures of the main surfaces on the crosssection of the machined layer has not been clearly defined. Therefore, the purpose of this work is to determine the impact of these parameters on changes in the cross-sectional area of the cutting layer. For this purpose, simulation tests were carried out using the direct method in the CAD environment.

\section{Simulation tests}

Simulation research was carried out by direct mapping of the tool in the CAD environment $[1,5]$. This method is based on mathematical models of solids used in CAD/CAM systems. The workpiece and the tool were modeled in a solid manner, which made it possible to carry out Boolean operations on these solids.

The simulation consisted of a discreet change in the mutual position of the workpiece models and the toroidal cutter motions resulting from the kinematics of the machining. In each subsequent discrete position, the part of the common solids representing the tool and the workpiece was a machined layer.

Because logic operations are carried out in a purely geometric way, the simulation does not take into account such phenomena as the elastic deformation of the machine-tool-holder-object-tool, vibrations and temperature, which occur in the actual machining process.

During the simulation, interference of the workpiece and tool was determined in the subsequent discrete positions of the tool. It was necessary to perform two Boolean operations: product and subtraction. The model tool was placed in a specific place in the CAD system workspace and was copied from each place to each subsequent discrete location. This technique eliminates numerical error associated with logical operations.

Model of the toroidal cutter was created on the basis of its operating surface (fig. 4).

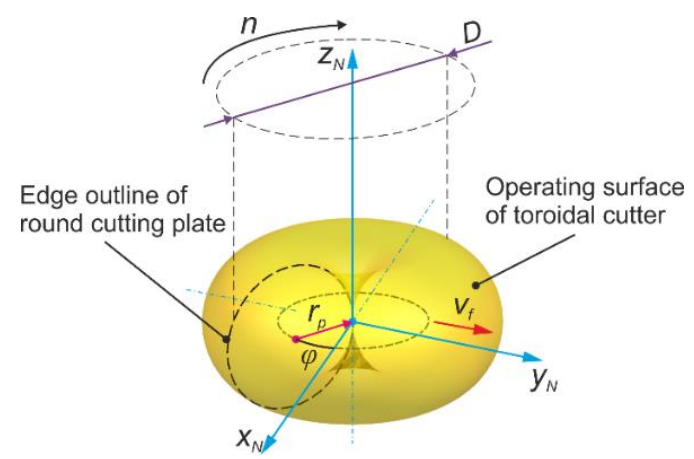

Fig. 4. Toroidal cutter model created on the basis of the operating surface 
The operating surface is the surface that the cutting edges of the cutter travel in space as a result of the main movement around the spindle axis of the milling head. The cutter moved in relation to the workpiece with movements that resulted from the actual kinematics of the spindle feeds with a fixed step. In the case under consideration, this movement was consistent with the feedrate vector $v_{f}$, while the discretization step, i.e. change of the mutual position of the cutting surface of the cutter and workpiece, was assumed to be equal to the feedrate per blade value $f_{z}$.

Solid models of the analyzed surfaces were in the form of an initial blank with an assumed excess $q_{b}$ (fig. 5 ). Surfaces of these models were obtained as a result of direct simulation of the CAD mapping of the surface of the toroidal cutter. The 3D-CAD models were accepted for simulation tests, corresponding to the cuboid of dimensions $a$ and $b$, limited by the convex-concave and concave-convex surface, with given radii of curvatures in the feed direction $\rho_{1}$ and in the direction perpendicular to the feed $\rho_{2}$. a)

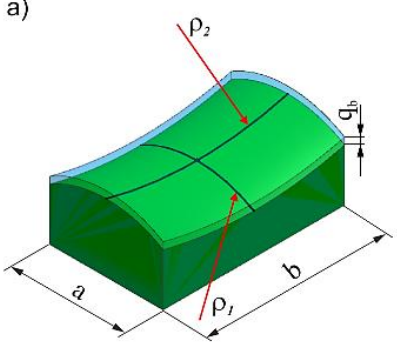

b)

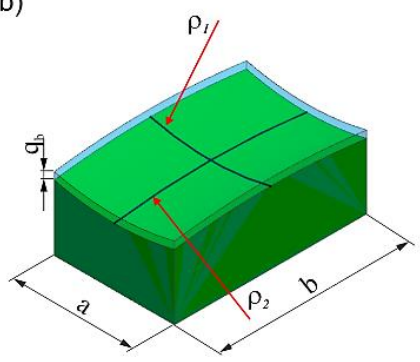

Fig. 5. 3D-CAD models of the analyzed surfaces: a) convexconcave, b) concave-convex

\section{Test conditions}

The research was carried out in two stages. The first one simulated the process of five-axis machining of the convex-concave surface, while the second stage - the concave-convex surface - reflecting the ridge and the bed of the turbine blade.

\section{TABLE I. Simulation study conditions}

\begin{tabular}{|l|c|c|}
\hline \multicolumn{1}{|c|}{ Parameters } & $\begin{array}{c}\text { Convex-concave } \\
\text { surface machining }\end{array}$ & $\begin{array}{c}\text { Concave-convex } \\
\text { surface machining }\end{array}$ \\
\hline $\mathrm{a}_{\mathrm{p}}, \mathrm{mm}$ & 0,25 & 0,25 \\
\hline $\mathrm{a}_{\mathrm{e}}, \mathrm{mm}$ & 1,5 & 1,5 \\
\hline $\mathrm{f}_{\mathrm{z}}, \mathrm{mm} / \mathrm{ostrze}$ & 0,26 & 0,26 \\
\hline$\rho_{1}, \mathrm{~mm}$ & $\rho_{1} \in<25 \div 400>$ & $\rho_{1} \in<40 \div 120>$ \\
\hline$\rho_{2}, \mathrm{~mm}$ & $\rho_{2} \in<800 \div 2000>$ & $\rho_{2} \in<800 \div 2000>$ \\
\hline$\alpha,^{\circ}$ & $\alpha \in<3 \div 18>$ & $\alpha \in<7 \div 23>$ \\
\hline$\beta,^{\circ}$ & $\beta \in<0 \div 15>$ & $\beta \in<0 \div 15>$ \\
\hline
\end{tabular}

Simulation tests were carried out applying the technological parameters adopted according to the recommendations of the test tool manufacturer (toroidal cutter R300-016B20L-08L Sandvik Coromant) and material of the object (Inconel 718 alloy based on nickel). Ranges of the machining process variables - leading angle $\alpha$, angle of inclination $\beta$ and radii of curvature $\rho_{1}$ and $\rho_{2}$ - assumed on the basis of analysis of different geometries of turbine blades (Table I).

To determine the significance of the influence of one or several input factors on the resultant factor, exploratory studies were conducted based on a properly selected research program. Most often, two groups of programs are used in the impact significance studies. The first one includes programs related to variance analysis - randomized static programs. The condition for their use is the lack of interaction of input factors. The second group is: a randomized program - random balance sheet, i.e. a randomized static program (supersaturated), and a determined (partial saturated) static program of Plackett-Burman.

Due to the presence of four input factors and at the same time the assumption of interaction between them, and because the number of experiments in the simulation environment is equal to the number of variables in the model, simulation studies were carried out according to the Plackett-Burman program. The simulation environment was a Siemens NX system CAD module.

At each stage, the constant parameters were: cutting depth $a_{p}$, cutting width $a_{e}$, cutting speed $v_{c}$ and feedrate per blade $f_{z}$. The diameter of the toroidal cutter $D=16$ $\mathrm{mm}$ and radius of the circular cutting insert $r_{p}=4 \mathrm{~mm}$ also remained constant. Variable parameters in the set range were: advance angle $\alpha$, inclination angle $\beta$, radius of curvature in the feed direction $\rho_{1}$ and radius of curvature in the direction perpendicular to the feed $\rho_{2}$.

\section{Test results}

- Determination of the significance of $\alpha, \beta, \rho_{1}, \rho_{2}$ influence on the cross-section of the cutting layer of the convex-concave surface. The significance of the influence of the advance angle $\alpha$, angle of inclination $\beta$, radius of curvature in the direction of feed $\rho_{1}$ and radius of curvature in the direction perpendicular to the feed $\rho_{2}$ on the cross-section of the machined layer was determined at the adopted significance level of $T=0.05$. In the next steps, the variance of the experiment, number of freedom degrees, values of $t$-Student variables coefficients studied and critical value of of $a_{k r}$ variables coefficients tested at the adopted significance level $T$, were calculated. Subsequently, the significance coefficients with the critical value were compared with the real variables. This provided the basis for the assessment of significance of the impact of tested variables on the cross-section of the machined layer (Table II).

\section{TABLE II. Evaluation of the significance of tested variables}

\begin{tabular}{|c|c|}
\hline Inclination angle, $\beta$ & Insignificant \\
\hline Advance angle, $\alpha$ & Significant \\
\hline Curvature radius, $\rho_{1}$ & Significant \\
\hline Curvature radius, $\rho_{2}$ & Insignificant \\
\hline
\end{tabular}

Based on the simulation results and calculations covered by the test plan, it was found that the crosssection of the cut layer in five-axis milling of the convexconcave surface is significantly affected only by the angle of advance $\alpha$ and the radius of curvature $\rho_{1}$ in the direction of feed. The influence of these important parameters on the cross-sectional area of the machined cutting layer is shown in fig. 6. 


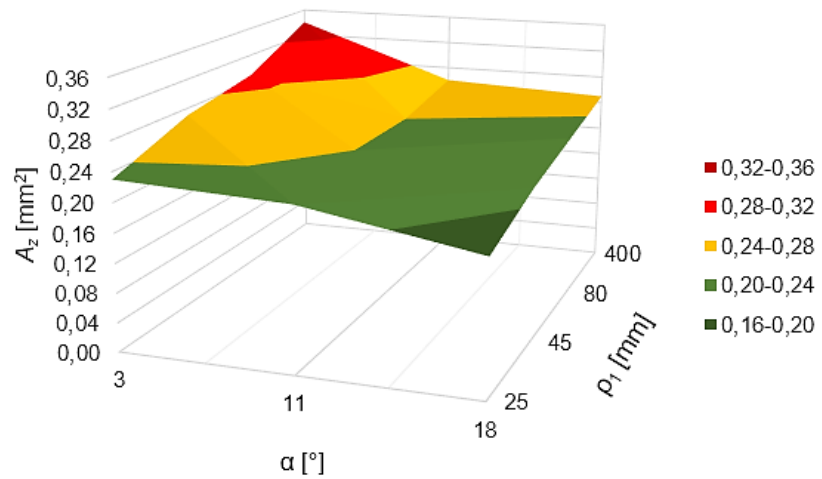

Fig. 6. Influence of the advance angle $\alpha$ and the radius of curvature $\rho_{1}$ on the cross-sectional area of the transverse cutting layer $A_{z}$ during machining of the convex-concave surface

The graph shows that the advance angle $a$ significantly influences the cross-sectional area of the cutting layer $A_{z}$, rather than the radius of curvature $\rho_{1}$. Increasing the value of angle $\alpha$ from $3^{\circ}$ to $18^{\circ}$ caused a decrease in the cross-sectional area of the cutting layer by approximately $20 \%$ for the surface, the processed contour of which has a radius of $\rho_{1}=25 \mathrm{~mm}$, and about $25 \%$ for a surface, of which contour has a radius of $\rho_{1}=$ $400 \mathrm{~mm}$. Increasing the value of the radius of curvature $\rho_{1}$ from $25 \mathrm{~mm}$ to $400 \mathrm{~mm}$ caused an increase in the cross-sectional area of the cutting layer by about $15 \%$ for angle $\alpha=3^{\circ}$ and $10 \%$ for angle $\alpha=18^{\circ}$. The influence of the inclination angle $\beta$ and radius of curvature $\rho_{2}$ on the cross-sectional area of the transverse cutting layer $A_{z}$ is of little importance.

- Determination of the significance of $\alpha, \beta, \rho_{1}, \rho_{2}$ influence on the cross-section of the cutting layer of the concave-convex surface. In an analogous manner, as described in the previous sub-chapter, the significance of the influence of advance angle $\alpha$, angle of inclination $\beta$, radius of curvature in the feed direction $\rho_{1}$ and radius of curvature in the direction perpendicular to the feed $\rho_{2}$ on the cross-section of the cut surface of the concave-convex surface, were determined. The assessment of this impact is depicted in Table III.

Some limitation in the simulation of the concaveconvex surface was the value of minimal angle of advance $\alpha_{\min }$, which was calculated from previously given relationship for the smallest radius of curvature $\rho_{1}$ of the surface contour to be machined in the direction of the tool feed. In order to avoid undercutting, a minimum advance angle $\alpha_{\min }=7^{\circ}$ was calculated, which should be used in the simulation of the concave-convex surface using the R300-016B20L-08L Sandvik Coromant toroidal cutter.

TABLE III. Evaluation of the significance of tested variables

\begin{tabular}{|c|c|}
\hline Inclination angle, $\beta$ & Insignificant \\
\hline Advance angle, $\alpha$ & Significant \\
\hline Curvature radius, $\rho_{1}$ & Significant \\
\hline Curvature radius, $\rho_{2}$ & Insignificant \\
\hline
\end{tabular}

Based on the results of the machining simulation and the calculations covered by the test plan, it was found that, similarly to the convex-concave surface treatment, both the advance angle $\alpha$ and radius of curvature $\rho_{1}$ significantly influence the cross-cut of the cutting layer.

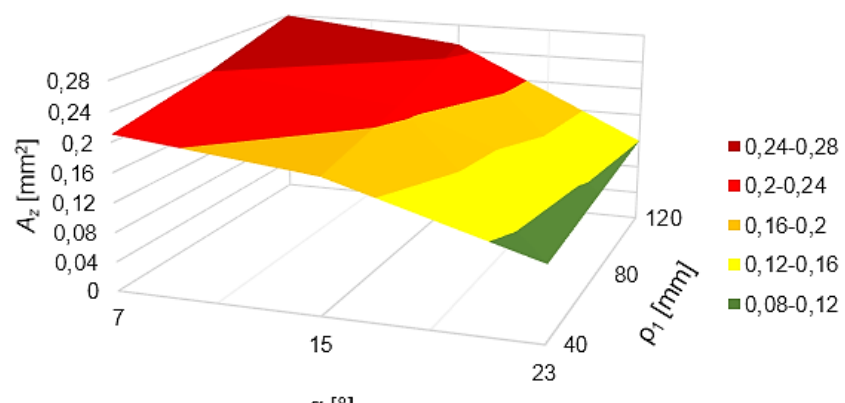

$\alpha\left[{ }^{\circ}\right]$

Fig. 7. Influence of the advance angle $\alpha$ and radius of curvature $\rho_{1}$ on the cross-sectional area of the transverse cutting layer $A_{z}$ during machining of the concave-convex surface

The influence of advance angle $\alpha$ and radius of curvature $\rho_{1}$ on the cross-sectional area of the cutting layer $A_{z}$ is shown in fig. 7 .

The graph shows that, similarly to the simulation of the convex-concave surface machining, in this case, the cross-sectional area of the cutting layer $A_{z}$ is influenced to a much greater extent by the angle of advance $\alpha$ than the radius of curvature $\rho_{1}$. Increasing the value of angle $\alpha$ from $7^{\circ}$ to $23^{\circ}$ caused a decrease in the cross-sectional area of the cutting layer by about $30 \%$ for the surface, the radius of which in the feed direction $\rho_{1}=40 \mathrm{~mm}$ and $35 \%$ for the surface with the radius of the processed contour $\rho_{1}=120 \mathrm{~mm}$. Increasing the radius of curvature $\rho_{1}$ from $40 \mathrm{~mm}$ to $120 \mathrm{~mm}$ caused an increase in the cross-sectional area of the cutting layer by approximately $25 \%$ for the advance angle $\alpha=7^{\circ}$ and about $10 \%$ for the advance angle $\alpha=23^{\circ}$.

As it results from the calculations included in the test plan, the influence of the inclination angle $\beta$ and radius of curvature $\rho_{2}$ on the cross-sectional area of the transverse cutting layer $A_{z}$ is of little importance.

\section{Conclusions}

Based on simulation studies of the process of five-axis milling of sculptured surfaces with toroidal cutter and evaluation of the significance of influence of advance angle $\alpha$, angle of inclination $\beta$ and radius of curvature $\rho_{1}$ in the direction of feed and radius of curvature $\rho_{2}$ in the direction perpendicular to the feed, it was found that the cross-section of the cutting layer in concave-convex and convex-concave surface machining are significantly affected only by the angle of advance $\alpha$ and radius of curvature $\rho_{1}$ in the direction of the tool feed. Additionally, the cross-section of the cutting layer can be significantly influenced by the kinematic parameter of the advance angle $\alpha$.

The obtained results indicate new possibilities in the field of tool axis orientation control and provide the basis for development of a new CAM strategy. It should be based on the analysis of the geometric interpenetration of the milling work surface with the machined surface and the resulting cross-section of the cutting layer. This method should also enable stabilization of the crosssectional area of the cutting layer, and thus the values of cutting forces and parameters of the accuracy of sculptured surfaces. The work carried out by the authors of this article is underway in this area. 


\section{REFERENCES}

1. Budak E., Ozturk E., Tunc L.T. "Modelling and simulation of 5-axis milling processes". CIRP Annals - Manufacturing Technology. 58 (2009): pages 347-350.

2. Burek J., Żyłka Ł., Gdula M. "Cross section of the cutting layer in the simultaneous five axis free surfaces machining". Archives of Mechanical Technology and Automation. 34, 4 (2015): pages 11-24.

3. Burek J., Żyłka Ł., Gdula M., Płodzień M. „Wpływ orientacji osi freza toroidalnego na składowe siły skrawania w pięcioosiowej obróbce łopatki turbiny". Mechanik CD. 8-9 (2015): pages 764-774.

4. Cao L.X., Gong H., Liu J. "The offset approach of machining free form surface Part 2: Toroidal cutter in 5-axis NC machine tools". Journal of Materials Processing Technology. 184 (2007): pages 6-11.

5. Gdula M. "Proces symultanicznego pięcioosiowego frezowania powierzchni złożonych frezem toroidalnym". Praca doktorska. Rzeszów 2017.

6. Gilles P., Monies F., Walter R. "Optimum orientation of a torus milling cutter: Method to balance the transversal cutting force". International Journal of Machine Tools and Manufacture. 47 (2007): pages 2263-2272.

7. Gilles P., Cohen G., Monies F. "Torus cutter positioning in five-axis milling using balance of the transversal cutting force". International Journal Advanced Manufacturing Technology. 66 (2013): pages 965-973.

8. Mucha M. „Optymalizacja wydajności obróbki elementów o zarysie krzywoliniowym ze stopu tytanu". Praca doktorska, Kraków, 2015. 